\title{
Impact of donor and recipient adiposity on placental and fetal growth in adolescent sheep
}

\author{
Jacqueline M Wallace, John S Milne, Clare L Adam and Raymond P Aitken \\ The Rowett Institute, University of Aberdeen, Aberdeen, UK \\ Correspondence should be addressed to J M Wallace; Email: Jacqueline.Wallace@abdn.ac.uk
}

\begin{abstract}
The influence of maternal obesity during oocyte development and its putative interaction with nutrient reserves at conception on pregnancy outcome were examined in an adolescent sheep model. Donor ewes were nutritionally managed to achieve contrasting adiposity (control (CD)/obese (ObD)) for 6 weeks prior to superovulation and inseminated by a non-obese sire. Morulae from 6 CD and $7 \mathrm{ObD}$ were transferred in singleton into adolescent recipients of identical age but differing adiposity, classified as relatively fat or thin respectively. Thereafter, all were overnourished to promote rapid growth/adiposity ( $2 \times 2$ design, $13 / 14$ pregnancies/group). A fifth recipient group of intermediate adiposity received embryos from another $5 \mathrm{CD}$, was offered a moderate intake to maintain adiposity throughout gestation and acted as controls for normal pregnancy outcome (optimally treated control (OTC), 19 pregnancies). Donor obesity did not influence ovulation, fertilisation or recovery rates or impact embryo morphology. Gestation length and colostrum yield were unaffected by donor or recipient adiposity and were reduced relative to OTC. Total fetal cotyledon and lamb birth weights were independent of initial donor adiposity but reduced in relatively thin vs relatively fat recipients and lower than those in the OTC group. In spite of high placental efficiency, the incidence of fetal growth restriction was greatest in the thin recipients. Thus, maternal adiposity at conception, but not pre-conception maternal obesity, modestly influences the feto-placental growth trajectory, whereas comparison with the OTC indicates that high gestational intakes to promote rapid maternal growth remain the dominant negative influence on pregnancy outcome in young adolescents. These findings inform dietary advice for pregnant adolescent girls.

Reproduction (2017) 153 381-394
\end{abstract}

\section{Introduction}

Birth weight is a valuable aggregate of fetal nutrient supply and a robust prognosticator of health and wellbeing immediately after delivery and throughout the life-course. Our focus is the low end of the birth weight spectrum as these babies are most likely to die in infancy or experience a range of physical and development issues that can limit their life chances (Sharma et al. 2016). Further, low birth weight is a risk factor for the later development of a number of life-limiting diseases that drain health service resources including diabetes, stroke and cardiovascular disease, as such decreasing the proportion of babies born too early and/or too small is a pressing public health objective (WHO 2012, Hanson \& Gluckman 2015).

The most consistent risk of poor outcome is when pregnancy coincides with adolescence. Accordingly both population-wide and single-centre studies in low-, middle- and high-income countries reliably report a higher risk of spontaneous miscarriage, premature delivery, low birth weight and neonatal mortality in adolescent compared with adult pregnancies
(Shrimetal.2011, Malabareyetal.2012, Ganchimegetal. 2013, Kozuki et al. 2013, Weng et al. 2014, Torvie et al. 2015). These hazards are most pronounced in very young girls when pregnancy potentially overlaps with continued or incomplete growth of the mother, setting up a competition for nutrients between the maternal body and the gravid uterus, which results in attenuated fetal growth (Frisancho et al. 1985, Scholl et al. 1994, 1997, Frisancho 1997). A similar maternal-fetal growth competition for nutrients has been partly reproduced in a highly controlled sheep model whereby overfeeding young singleton-bearing adolescents throughout pregnancy promotes high gestational weight gains and supports continued maternal growth and increased adiposity. These rapid maternal growth rates are associated with a greater incidence of miscarriage and stillbirth and robustly result in the premature delivery of low birth weight lambs compared to control-fed (slowgrowing) adolescents of the same age (Wallace et al. 2004). In this overnourished model, defects in early placental development including lower cellular proliferation, reduced blood vessel development and 
impaired secretory function progressively compromise the growth trajectory and haemodynamic function of the placenta. Consequently by the final third of gestation and regardless of nutrient excess in the mother, the small size of the placenta and associated reduction in uteroplacental blood flows and nutrient uptakes limit fetal nutrient supply (Wallace et al. 2006a). This leads to a slowing of fetal growth (Carr et al. 2012) and at parturition about $50 \%$ of these lambs are classified as prenatally growth restricted relative to the normal birth weight offspring of the optimally nourished controls (Wallace et al. 2004, 2006a).

In the foregoing initial sheep studies, we concentrated on varying dietary intake and hence growth status immediately after pregnancy had been established and thus the adolescents were of similar age, weight and adiposity at conception. Acknowledging that adolescent girls enter pregnancy from diverse nutritional backgrounds and with different nutrient reserves at conception, we have additionally shown that, irrespective of gestational intake and growth status, adolescents who were relatively light and thin at conception gave birth to lighter lambs than those who were heavier and fatter (Wallace et al. 2010). This reduction in fetal growth was again mediated by the placenta, implying a direct effect of nutrient reserves at conception on the metabolism of the dam and her early uterine environment, leading to a compromised placental growth trajectory. However, variable nutrient intakes and/or nutritional status in the peri-conception period may additionally contribute to pregnancy outcome via effects on follicle recruitment, oocyte maturation, fertilisation and early embryo development (Sinclair \& Watkins 2014). As pregnancy is normally a continuum from oocyte to fetus to delivery, it is difficult to segregate the influence of nutrition at any precise stage due to potential carry over effects between sequential stages. However, in our animal model, by using assisted conception procedures, we are able to uncouple pre-, peri- and post-conception nutritional exposures to assess their separate or interdependent influences.

Herein, we evaluate whether the nutritional status of the embryo donor ewe (relatively obese vs normal) interacts with that of the embryo recipient (relatively fat vs thin) to influence conception rate, fetal growth, pregnancy outcome and early offspring growth in adolescent animals that were overnourished throughout pregnancy. Obese vs control (normal adiposity) donor ewes were used because obesity impacts fertility with negative effects on follicle recruitment, oocyte viability, fertilisation and early embryo development reported in animal models and in humans seeking assistance to conceive via assisted reproduction technologies (ART, Gonzalez-Anover et al. 2011, Purcell \& Moley 2011, Kumbak et al. 2012, Sinclair \& Watkins 2014, Velazquez 2015). Moreover, in adult humans conceiving naturally, peri-conception obesity is widely associated with a plethora of pregnancy complications including hypertensive disorders, gestational diabetes, stillbirth, fetal malformations, premature delivery and derangements in fetal growth resulting in either high birth weight or relative fetal growth restriction (McDonald et al. 2010, Anderson et al. 2013, Aune et al. 2014, Lutsiv et al. 2015, Marchi et al. 2015). Therefore, this study tests the hypothesis that pregnancy rate and conceptus development would be most negatively disturbed in pregnancies generated from embryos of relatively obese compared with control donors, and this would be exacerbated in adolescent recipients who were relatively thin compared with those who were fatter at conception.

\section{Materials and methods}

\section{Experimental design}

All procedures were licensed under the UK Animals (Scientific Procedures) Act of 1986 and approved by the Rowett Institute's

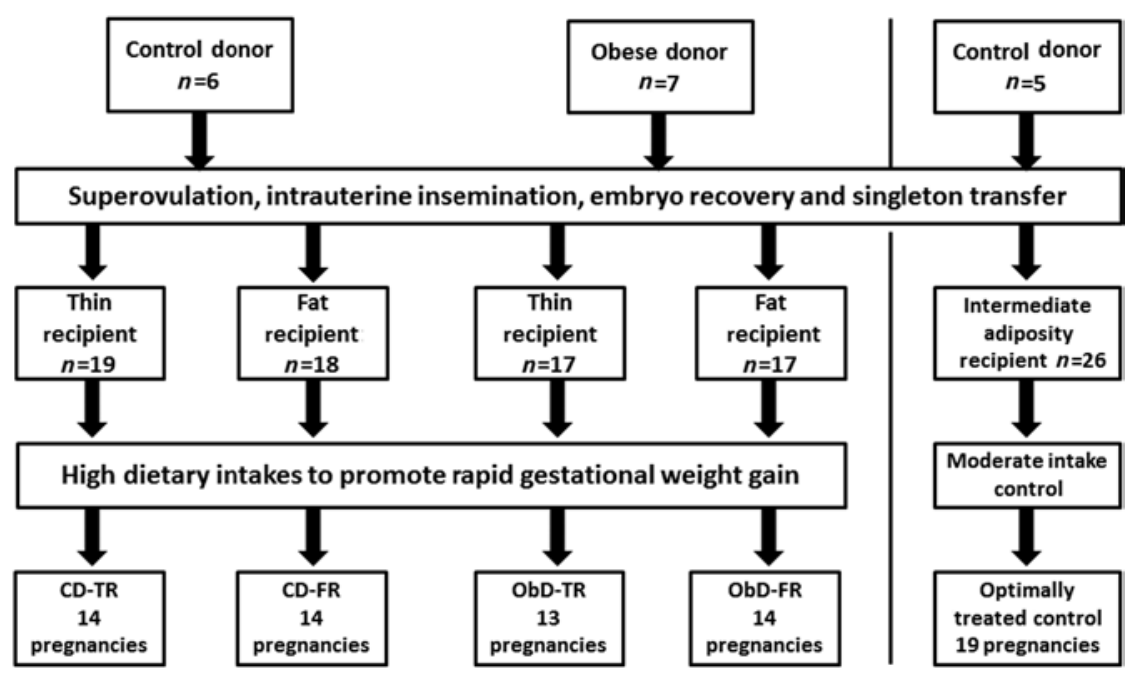

Reproduction (2017) 153 381-394
Figure 1 Overview of experimental design. 
Ethical Review Committee. The main design is a $2 \times 2$ factorial to examine the impact of embryo donor adiposity during oocyte development vs embryo recipient nutritional status at conception on pregnancy outcome at term. These adolescent ewes were subsequently overnourished throughout gestation to promote rapid maternal body growth. A fifth contemporaneous group of optimally treated control adolescents acted as a reference point for normal fetal growth (Fig. 1).

\section{Animals: donors}

Adult ewes (Border Leicester $\times$ Scottish Blackface) of equivalent age and parity ( 2.5 years old and 1 previous pregnancy/ lactation) destined to become potential embryo donors were selected from the Institute's flock, group housed and nutritionally manipulated by varying quantities of diet offered over a 3-month period to achieve different adiposity levels (control vs relatively obese). For the 4 weeks prior to starting superovulation protocols ( 6 weeks prior to embryo recovery), animals were individually housed under natural lighting conditions and offered maintenance rations of a complete diet (see below) to maintain weight and adiposity score. The latter was evaluated, based on manual palpation of lumbar spine, ribs and tail-head, by one experienced operator on a scale of $0-5$, where $0=$ extremely emaciated and $5=$ extremely obese, according to the criteria of Russel and coworkers (Russel et al. 1969). The accuracy of this scoring system has been validated against whole carcass chemical analyses and is sensitive to within 0.25 score units (Wallace et al. 1999). On the day prior to insemination, the adiposity (mean \pm S.E.M.) of potential control compared with relatively obese donors was $2.2 \pm 0$ units vs $3.4 \pm 0.11$ units, equivalent to approximately $22 \%$ and $33 \%$ body fat respectively (Russel et al. 1969). Donor ewes were adult rather than adolescent as their embryos are inherently more viable (Quirke \& Hanrahan 1977, McMillan \& McDonald 1985).

\section{Recipients}

Meanwhile two groups of adolescent ewe lambs of identical age ( 7.5 months) but markedly different adiposity scores were selected from another flock (Dorset Horn $\times$ Greyface) 4 weeks prior to assisted conception procedures, destined to become embryo recipients. During this 4 -week period, animals were individually offered maintenance rations of a complete diet to maintain their initial weight and thereby adiposity score. For ease of presentation, adolescents who were light and had a low adiposity score were classified as relatively thin, whereas those that were heavier and had a higher adiposity score were classified as relatively fat. Immediately prior to embryo transfer the adiposity score of these 'thin' vs 'fat' groups was $2.0 \pm 0$ and $2.7 \pm 0.02$ units equivalent to approximately $20 \%$ and $26 \%$ body fat respectively.

\section{Embryo transfer}

Using techniques described previously (Wallace et al. 1997), donor ewes were intrauterine inseminated on Day 0 by a single sire with optimal adiposity for breeding (Dorset Horn, body score 3) and embryos were recovered at laparotomy on Day 4 after oestrus. Corpora lutea were counted to establish ovulation rate and embryos morphologically graded under a stereomicroscope. Embryos classified as good early morula (grade 1) and from either control or obese donors were synchronously transferred singly into the uterus of either fat or thin recipients (main study, $2 \times 2$ ). A contemporaneous third group of adolescents of intermediate or control adiposity $(2.3 \pm 0.01$ units, $23 \%$ body fat) received embryos from control donors (optimally treated control (OTC) reference group).

Embryo transfers were carried out on six separate days during the mid-breeding season. Equivalent numbers of fat and thin adolescents were set-up and synchronised as potential recipients for each day (7 or 8 animals per adiposity classification per day). On the first and third day, potential embryo donors were controls, and on the second and fourth days, donors were obese. On each of these days, the aim was to transfer equal numbers of embryos from an individual donor into the two groups of recipients while taking care not to over-represent a particular donor's genetics. Thus, a maximum of eight embryos per donor were used in the study (average 5.5, range 2-8). The fifth and sixth days were reserved for the transfer of control donor embryos into the control (intermediate) adiposity recipients destined to receive a control dietary intake (OTC group). Three potential embryo donors $(2 \times$ control and $1 \times$ obese $)$ had either regressing corpora lutea or $100 \%$ unfertilised oocytes, and these animals took no further part in the study. Similarly, a small number of potential recipients either failed to ovulate or had regressing corpora lutea when examined by laparoscope prior to embryo transfer and were discharged from further study. For the main study, 37 and 34 embryos representative of 6 control and 7 obese adult donor genetics were transferred into 71 adolescent recipients $(36 \times$ thin and $35 \times$ fat). This yielded 4 main study groups, namely control donor-thin recipient (CD-TR, $n=19$ ), control donor-fat recipient (CD-FR, $n=18$ ), obese donor-thin recipient (ObD-TR, $n=17$ ) and obese donor-fat recipient (ObD-FR, $n=17$ ). A further 26 embryos representative of a further 5 control donor ewes' genetics were transferred into the control adiposity reference group destined to become the OTC group (Fig. 1).

\section{Nutritional management}

The complete diet used throughout supplied $12 \mathrm{MJ}$ metabolisable energy (ME) and $140 \mathrm{~g}$ crude protein per $\mathrm{kg}$ and was offered in two equal portions at 08:00 and 16:00 h daily (see Wallace et al. 2006b for full details of the diet composition and analyses). This diet was used to achieve the contrasting nutritional states in donors and recipients before conception and in recipients during pregnancy and lactation. After embryo transfer, all recipients in the main four donor $\times$ recipient adiposity groups were offered high dietary intakes to promote rapid gestational weight gain and increasing adiposity throughout gestation (overnourished; equivalent to $\sim 2 \times$ estimated ME requirements for optimum conceptus growth in ewes of this age and genotype). After a 3-day postsurgery re-alimentation period, high intakes were achieved by increasing the level of complete diet offered gradually over 
a 2-week period until the level of the daily food refusal was $\sim 15 \%$ of the total offered (equivalent to ad libitum intakes). The dietary level offered in the OTC group was calculated to maintain normal maternal adiposity throughout gestation (i.e. no change from initial starting adiposity) and hence meet the estimated ME requirements for optimum conceptus growth (AFRC 1993). To achieve this objective, the OTC group was fed to promote a modest maternal weight gain of $\sim 75 \mathrm{~g}$ per day during the first two-thirds of gestation, followed by stepwise increases in maternal intake during the final third of gestation, calculated to meet the increasing demands of the developing fetus. During pregnancy, the level of food offered was reviewed three times weekly and adjusted, on an individual basis as and when appropriate, on the basis of daily food refusal rates (overnourished groups) and adiposity score (OTC group). After parturition, all ewes were offered the complete diet to appetite (i.e. ad libitum) to maximise milk availability. For the OTC dams, this was achieved stepwise over a period of approximately 10 days. Recipient ewes were weighed fortnightly, and external adiposity score was assessed approximately monthly throughout pregnancy. Ewes were also weighed $\sim 24 \mathrm{~h}$ after parturition and at the end of lactation (77 days).

\section{Conception rate, parturition management and neonatal care}

Conception rate was determined by transabdominal ultrasonography at Day 50 of gestation. Pregnancy outcome was determined after spontaneous delivery, and ewes were supervised throughout the expected delivery period from Day 135 onwards (the earliest point commensurate with live birth in overnourished adolescents of this genotype). A standardised proactive regimen of neonatal care was used to prevent high neonatal mortality due to prematurity and impaired passive immunity and/or nutrient intake secondary to inadequate colostrum supply (Wallace et al. 1996). Lambs were dried and weighed and girth at the umbilicus was measured after delivery. The height measurement was delayed until $\sim 12 \mathrm{~h}$ after birth. Ewe colostrum yield was measured before lamb suckling and within $30 \mathrm{~min}$ of parturition. After intravenous injection of oxytocin (Oxytocin-S 10 i.u. per ewe; Intervet Ltd, Cambridge, UK), ewes were milked by hand until all the colostrum had been removed from the udder. The colostrum was weighed, sampled for IgG analysis and then fed to the ewe's own lamb by bottle or feeding tube at a rate of $50 \mathrm{~mL} / \mathrm{kg}$ body weight. In cases where the dam had insufficient colostrum, frozen pooled ewe colostrum collected previously immediately after birth (Day 145-147 of gestation) from optimally nourished adult twin-bearing ewes was substituted to ensure lamb survival. All lambs were weighed at 4 hourly intervals throughout the first $72 \mathrm{~h}$ of life and at 8 -h intervals from 72 to $168 \mathrm{~h}$. Any lamb which failed to suckle or gain weight over an 8 -h period was offered supplementary colostrum (first $24 \mathrm{~h}$ ) or ewe milk until the ewelamb bond and appropriate lactation were established (by $120 \mathrm{~h}$ after birth in all cases). The frequency of supplementary feeds per lamb was recorded. To further reduce the risk of infection, each lamb's navel was dipped in iodine at birth and at $12 \mathrm{~h}$ after delivery, and all lambs received intramuscular vitamin E/selenium supplementation at birth and prophylactic antibiotics for 5 days. After the placenta (fetal cotyledons and membranes) was delivered, its weight was recorded, and then the cotyledons were dissected, counted and weighed. Lamb weight and height were measured weekly throughout the 11-week lactation. For both parameters, absolute growth rate (AGR) was linear and was recorded as the slope of the line of best fit, determined by linear regression analysis. Current FGR (CFGR) at weekly intervals was calculated as the AGR for 0-77 days divided by the value of a parameter (weight or height) at the start of each 7-day period.

\section{Blood sampling and biochemical analysis}

Blood samples were collected by jugular venepuncture approximately $3 \mathrm{~h}$ after the morning feed into heparinised or non-treated vacutainers. Embryo donors were sampled once 2 days prior to embryo recovery, whereas embryo recipients were sampled at $\sim 28$-day intervals from Day 0 to 135 of gestation. For embryo donors, the heparinised blood sample was centrifuged, the plasma was harvested and stored at $-20^{\circ} \mathrm{C}$ until glucose, leptin, non-esterified fatty acids (NEFA), urea, total protein, triglycerides, total cholesterol, low-density lipoprotein (LDL) and high-density lipoprotein (HDL) cholesterol concentrations were determined. The non-heparinised sample was collected, allowed to clot at room temperature for $2 \mathrm{~h}$, wrung with a needle, refrigerated overnight and centrifuged to yield a serum sample for iron analysis. For the embryo recipients, maternal haemoglobin content was immediately measured in the heparinised blood sample in duplicate using a Radiometer OSM-3 haemoximeter (Radiometer, Copenhagen, Denmark), whilst haematocrit was determined in duplicate after blood was drawn into capillary tubes and centrifuged at room temperature at 13,000 $\mathrm{g}$ (Micro Haematocrit centrifuge, Hawksley and Sons Ltd, England, UK). The residual plasma was analysed as detailed previously except leptin, which was only measured in the pre-transfer and final late gestation samples. A separate heparinised blood sample was collected in late gestation (d130) to analyse plasma viscosity, and at the same stage, a further non-heparinised sample was collected for serum iron analysis. Plasma leptin was measured within a single assay in duplicate as described previously (Marie et al. 2001). The limit of detection was $0.4 \mathrm{ng} / \mathrm{mL}$, and the intra-assay coefficient of variation was $7.5 \%$. Plasma viscosity was measured at $25^{\circ} \mathrm{C}$ using a Coulter capillary viscometer (Cooke \& Stuart 1988). All other biochemical measurements in blood or plasma were carried out using an automated clinical analyser (KONE) and kits were supplied by the manufacturer (Labmedics, Manchester, UK). Variation between duplicates was $<5 \%$ in all cases. Colostrum IgG content was determined using an ovine-specific ELISA as described previously (Wallace et al. 2006b): intra- and interassay coefficients of variation were $4.2 \%$ and $6.4 \%$.

\section{Data analysis}

All statistical comparisons were made using Minitab (version 17, State College, PA, USA). Embryo donor hormone and metabolic blood parameters, anthropometry, ovulation and embryo recovery rates were compared by Student's $t$ test. 
Table 1 Donor ewe anthropometry, metabolic status and fecundity at embryo recovery.

\begin{tabular}{|c|c|c|c|}
\hline & Control donor $(n=11)$ & Obese donor $(n=7)$ & $P$ value \\
\hline Weight (kg) & $71.3 \pm 1.38$ & $88.0 \pm 1.99$ & $<0.001$ \\
\hline Adiposity score & $2.25 \pm 0.00$ & $3.43 \pm 0.10$ & $<0.001$ \\
\hline \multicolumn{4}{|l|}{ Plasma } \\
\hline Glucose $(\mathrm{mmol} / \mathrm{L})$ & $3.4 \pm 0.09$ & $3.5 \pm 0.06$ & 0.403 \\
\hline $\mathrm{NEFA}(\mathrm{mmol} / \mathrm{L})$ & $0.23 \pm 0.034$ & $0.11 \pm 0.034$ & 0.031 \\
\hline Urea $(\mathrm{mmol} / \mathrm{L})$ & $7.53 \pm 0.310$ & $7.52 \pm 0.250$ & 0.959 \\
\hline Total protein $(\mathrm{g} / \mathrm{L})$ & $80.5 \pm 1.77$ & $86.1 \pm 1.41$ & 0.041 \\
\hline Triglycerides $(\mathrm{mmol} / \mathrm{L})$ & $0.20 \pm 0.017$ & $0.16 \pm 0.031$ & 0.262 \\
\hline Total cholesterol $(\mathrm{mmol} / \mathrm{L})$ & $1.78 \pm 0.116$ & $1.33 \pm 0.059$ & 0.001 \\
\hline LDL cholesterol $(\mathrm{mmol} / \mathrm{L})$ & $0.77 \pm 0.088$ & $0.40 \pm 0.033$ & 0.005 \\
\hline $\mathrm{HDL}$ cholesterol $(\mathrm{mmol} / \mathrm{L})$ & $0.93 \pm 0.043$ & $0.63 \pm 0.031$ & $<0.001$ \\
\hline Glycerol $(\mathrm{mmol} / \mathrm{L})$ & $37.9 \pm 6.43$ & $23.0 \pm 4.3$ & 0.109 \\
\hline Leptin $(\mathrm{ng} / \mathrm{mL})$ & $8.0 \pm 0.71$ & $15.9 \pm 1.69$ & $<0.001$ \\
\hline Serum iron $(\mu \mathrm{mol} / \mathrm{L})$ & $29.1 \pm 2.09$ & $25.4 \pm 1.22$ & 0.197 \\
\hline Ovulation rate (range) & $21.6 \pm 3.4(9-51)$ & $14.1 \pm 0.99(10-18)$ & 0.110 \\
\hline Oocyte/embryo recovery $(\%)$ & $72 \pm 6.5$ & $54 \pm 13.0$ & 0.192 \\
\hline Fertilisation rate $(\%)$ & $82 \pm 7.8$ & $92 \pm 5.8$ & 0.367 \\
\hline Grade 1 embryos (\%) & $61 \pm 11.9$ & $73 \pm 10.6$ & 0.478 \\
\hline
\end{tabular}

Values are mean \pm S.E.M. Significant $P$ values $(<0.05)$ are highlighted in bold.

Initial recipient conception rate, lamb gender ratio, colostrum adequacy and the incidence of lambs classified as growth restricted were compared using binary logistic regression. Lambs were classified as intrauterine growth restricted (IUGR) if birth weight was <2 s.D. below the mean birth weight of lambs in the OTC group, i.e. $<4195$ g. For the main $2 \times 2$ factorial, the impact of embryo donor adiposity during oocyte development and embryo recipient nutritional status at conception (and their interaction) on maternal (recipient) anthropometry and pregnancy outcome at term was compared using two-way ANOVA (General Linear Model). Adding donor identity as a covariate did not influence any aspect of pregnancy outcome $(P>0.223)$. Comparison of these four groups with the optimally treated controls was by oneway ANOVA followed post hoc by Tukey's method with confidence limits set at $1 \%$ to differentiate between groups. Both approaches were used to assess the differences in embryo recipient hormone and metabolic status at the point of embryo transfer and thereafter. As embryo donor adiposity (CD vs ObD) was without significant influence, the biochemical data for recipients receiving embryos from control or obese donors were combined, presented on the basis of recipient adiposity at conception/gestational intake and further analysed by oneway ANOVA and Tukey's method as described previously. For absolute and current fractional lamb growth rates, the ANOVA model included all possible combinations of embryo donor adiposity, recipient adiposity, prenatal growth status and offspring gender. As significant effects were overwhelmingly due to prenatal growth status (IUGR or normal birth weight) and to a lesser extent gender (males vs females) the offspring growth data are presented on this basis. Correlation coefficient analyses were by Pearson's product moment test.

\section{Results}

\section{Donor ewe anthropometry, biochemical/metabolic status and fecundity}

The nutritional manipulation of embryo donors achieved the desired contrasting adiposity status for those ewes producing transferrable grade embryos (Table 1). All ewes in the two groups of control donors had a body condition score of 2.25 and, as there were no differences $(P>0.215)$ in any of the blood parameters measured, data were combined. Relative to controls, obese donors were characterised by low circulating NEFA and lipid levels and high circulating leptin concentrations (Table 1). Donor adiposity (CD vs $\mathrm{ObD}$ ) did not significantly influence average ovulation, fertilisation or embryo recovery rates or the number of transferrable grade embryos obtained.

\section{Recipient ewe conception rate, anthropometry and metabolic status}

For the CD-TR, CD-FR, ObD-TR and ObD-FR groups, conception rate after embryo transfer was 74, 78, 76 and $82 \%$ respectively. The recipients $(n=16)$ that failed to become pregnant had received embryos representative of 9 donor ewes' genetics (1 or 2 embryos each). Conception rate was unaffected by donor or recipient adiposity category. Conception rate in the optimally treated controls was $73 \%$ and the embryos that failed to implant $(n=7)$ were from 4 control donors $(1,2$ or 3 embryos each). The nutritional manipulation of potential embryo recipients achieved contrasting weight and adiposity status maintained to the time of embryo transfer as per experimental design and is detailed for the ewes which conceived (Table 2). Animals classified as relatively fat were on average $18 \mathrm{~kg}$ heavier and 0.7 score units fatter (equivalent to $8.8 \%$ body fat) than the thin group at the beginning of pregnancy. For both categories, the complete diet was available ad libitum throughout pregnancy (i.e. overnourished) and although recipients initially categorized as thin exhibited a greater degree of weight and adiposity gain during gestation, particularly during the first third, they remained lighter and leaner at parturition than the initially fat recipients 


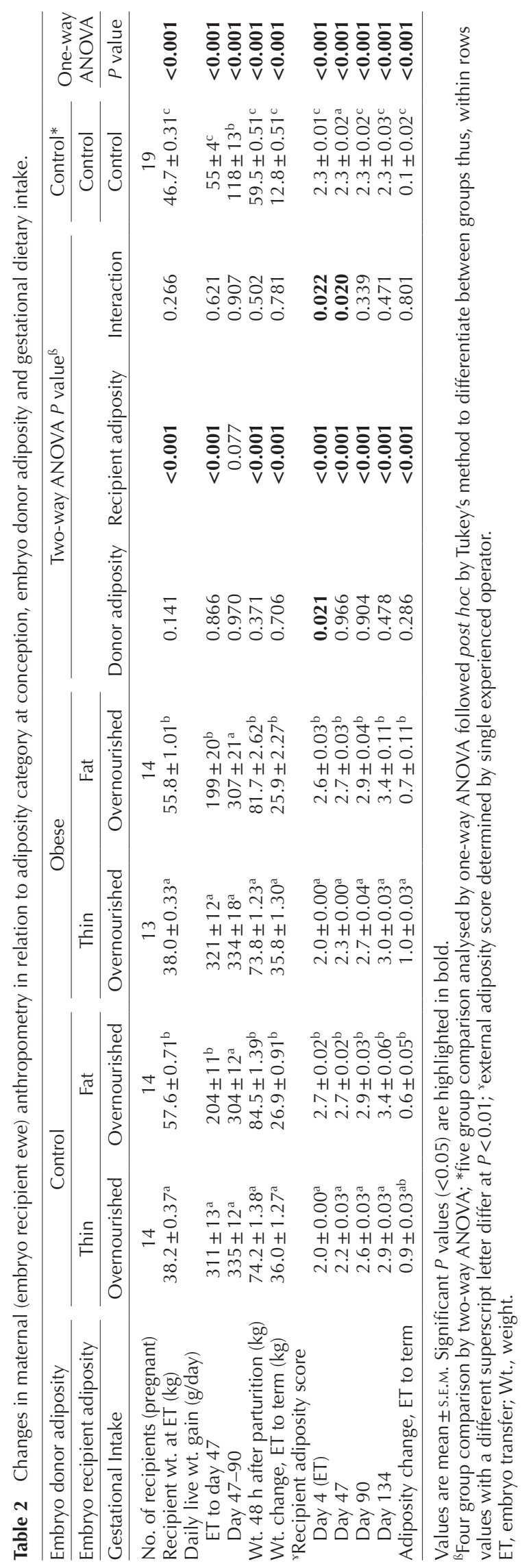

(Table 2). These changes in recipient anthropometry were largely independent of initial embryo donor category. In contrast and by design, the control adiposity recipients in the OTC group had an intermediate weight and adiposity level at embryo transfer and a relatively low rate of weight gain during the first two thirds of gestation, commensurate with their lower dietary intake. Consequently, maternal adiposity score was successfully maintained throughout gestation, as required (Table 2).

At the point of embryo transfer and relative to the control recipients in the OTC group, thin recipients had higher circulating NEFA, cholesterol, glycerol and urea and lower serum iron concentrations (Table 3). In contrast, relatively fat recipients had low circulating NEFA and cholesterol and higher glucose and leptin concentrations relative to both thin and control recipient groups. Recipient adiposity did not influence haematocrit or total haemoglobin content at embryo transfer. Changes in peripheral concentrations of plasma glucose, NEFA, urea and protein throughout gestation are shown in Fig. 2. As these blood parameters were independent of donor ewe adiposity the data are presented by initial recipient adiposity category and gestational intake only. Peripheral glucose concentrations reflected gestational intake had diverged by Day 30 of gestation $(P<0.001)$ and were higher in overnourished dams, irrespective of initial adiposity category, compared with the OTC group thereafter $(P=0.036$ to $<0.001)$. Plasma urea followed a similar pattern with divergent concentrations evident by Day 58 and maintained thereafter $(P<0.001)$. Circulating NEFA concentrations showed a marked decrease from baseline pre-embryo transfer levels to Day 30 of gestation in response to ad libitum feeding in both initially thin and fat recipients and were equivalent to the control-fed control adiposity group (OTC) at this stage. Thereafter, NEFA levels were largely similar in the fat recipient and OTC groups with one exception. At Day 86, immediately prior to the start of stepwise increases in maternal feed intake to meet conceptus requirements in the OTC group, NEFA levels were elevated $(P<0.001)$. Recipients who were relatively thin vs fat initially had lower $(P<0.001)$ NEFA concentrations from Day 58 to 133 of gestation reflecting their greater live weight gain and relative increment in adiposity score. Total plasma protein concentrations broadly reflected gestational intake and were greater $(P<0.001)$ in overnourished compared with control-fed OTC dams at Days 30, 58 and 86 of pregnancy. By late pregnancy, both LDL and HDL cholesterol concentrations also differentially reflected gestational intake, and glycerol levels were greatest in the overnourished groups who were relatively fat at conception (Table 3 ). In all three groups, plasma triglycerides increased between the start and the end of pregnancy to a similar degree, whereas total haemoglobin and haematocrit decreased over the same period with the largest differential observed in the OTC group. Plasma leptin concentrations did 
Table 3 Recipient ewe biochemical status immediately prior to embryo transfer and in late gestation.

\begin{tabular}{|c|c|c|c|c|}
\hline \multirow[b]{3}{*}{ Gestational intake } & \multicolumn{3}{|c|}{ Recipient adiposity at conception } & \multirow[b]{2}{*}{ One way ANOVA } \\
\hline & Control $(n=19)$ & $*$ Thin $(n=27)$ & *Fat $(n=28)$ & \\
\hline & Control & Overnourished & Overnourished & $P$ value \\
\hline \multicolumn{5}{|l|}{ Pre-embryo transfer } \\
\hline \multicolumn{5}{|l|}{ Plasma } \\
\hline Glucose (mmol/L) & $4.0 \pm 0.07^{\mathrm{a}}$ & $4.0 \pm 0.05^{\mathrm{a}}$ & $4.2 \pm 0.06^{b}$ & 0.003 \\
\hline NEFA $(\mathrm{mmol} / \mathrm{L})$ & $0.27 \pm 0.029^{\mathrm{a}}$ & $0.49 \pm 0.038^{b}$ & $0.09 \pm 0.013^{c}$ & $<0.001$ \\
\hline Urea $(\mathrm{mmol} / \mathrm{L})$ & $7.1 \pm 0.22^{\mathrm{a}}$ & $8.2 \pm 0.21^{b}$ & $7.3 \pm 0.19^{a}$ & $<0.001$ \\
\hline Total protein $(\mathrm{g} / \mathrm{L})$ & $74.3 \pm 1.13$ & $75.0 \pm 0.69$ & $72.3 \pm 0.88$ & 0.074 \\
\hline Triglycerides (mmol/L) & $0.20 \pm 0.012$ & $0.18 \pm 0.010$ & $0.17 \pm 0.012$ & 0.233 \\
\hline Total cholesterol $(\mathrm{mmol} / \mathrm{L})$ & $1.40 \pm 0.042^{\mathrm{a}}$ & $1.67 \pm 0.048^{\mathrm{b}}$ & $1.07 \pm 0.035^{c}$ & $<0.001$ \\
\hline LDL cholesterol (mmol/L) & $0.43 \pm 0.027^{a}$ & $0.51 \pm 0.022^{b}$ & $0.27 \pm 0.017^{c}$ & $<0.001$ \\
\hline HDL cholesterol $(\mathrm{mmol} / \mathrm{L})$ & $0.85 \pm 0.031^{\mathrm{a}}$ & $1.00 \pm 0.036^{\mathrm{b}}$ & $0.64 \pm 0.022^{c}$ & $<0.001$ \\
\hline Glycerol $(\mathrm{mmol} / \mathrm{L})$ & $35.9 \pm 3.66^{\mathrm{a}}$ & $54.9 \pm 3.90^{\mathrm{b}}$ & $26.5 \pm 1.82^{\mathrm{a}}$ & $<0.001$ \\
\hline Leptin $(\mathrm{ng} / \mathrm{mL})$ & $4.8 \pm 0.26^{\mathrm{a}}$ & $3.9 \pm 0.21^{\mathrm{a}}$ & $10.5 \pm 0.51^{\mathrm{b}}$ & $<0.001$ \\
\hline Serum iron $(\mu \mathrm{mol} / \mathrm{L})$ & $33.1 \pm 1.09^{a}$ & $28.3 \pm 0.87^{b}$ & $31.1 \pm 0.68^{\mathrm{a}}$ & 0.001 \\
\hline $\mathrm{Hb}$ & $14.3 \pm 0.22$ & $13.8 \pm 0.19$ & $13.8 \pm 0.12$ & 0.070 \\
\hline Hct & $47.3 \pm 1.25$ & $47.1 \pm 0.88$ & $47.0 \pm 0.55$ & 0.973 \\
\hline \multicolumn{5}{|l|}{ Late gestation (day 130-133) } \\
\hline \multicolumn{5}{|l|}{ Plasma } \\
\hline ¥Triglycerides (mmol/L) & $0.35 \pm 0.016$ & $0.30 \pm 0.024$ & $0.30 \pm 0.028$ & 0.386 \\
\hline Total cholesterol $(\mathrm{mmol} / \mathrm{L})$ & $1.58 \pm 0.041$ & $1.50 \pm 0.048$ & $1.54 \pm 0.044$ & 0.506 \\
\hline LDL cholesterol (mmol/L) & $0.45 \pm 0.023^{a}$ & $0.55 \pm 0.031^{\mathrm{ab}}$ & $0.57 \pm 0.033^{b}$ & 0.021 \\
\hline HDL cholesterol $(\mathrm{mmol} / \mathrm{L})$ & $0.91 \pm 0.021^{\mathrm{a}}$ & $0.75 \pm 0.021^{\mathrm{b}}$ & $0.78 \pm 0.018^{\mathrm{b}}$ & $<0.001$ \\
\hline Glycerol (mmol/L) & $39.9 \pm 2.24^{\mathrm{a}}$ & $34.4 \pm 2.56^{\mathrm{a}}$ & $57.4 \pm 4.17^{b}$ & $<0.001$ \\
\hline Leptin $(\mathrm{ng} / \mathrm{mL})$ & $5.3 \pm 0.41^{\mathrm{a}}$ & $17.0 \pm 1.23^{b}$ & $19.7 \pm 1.27^{\mathrm{b}}$ & $<0.001$ \\
\hline Serum iron $(\mu \mathrm{mol} / \mathrm{L})$ & $27.8 \pm 1.46$ & $28.9 \pm 1.25$ & $30.4 \pm 0.71$ & 0.290 \\
\hline${ }^{¥} \mathrm{Hb}(\mathrm{g} / \mathrm{dL})$ & $11.3 \pm 0.30^{\mathrm{a}}$ & $12.1 \pm 0.21^{\mathrm{ab}}$ & $12.3 \pm 0.25^{b}$ & 0.022 \\
\hline${ }^{¥} \mathrm{Hct}(\%)$ & $36.3 \pm 1.07$ & $38.9 \pm 0.69$ & $39.5 \pm 0.96$ & 0.055 \\
\hline Plasma viscosity (mPa) & $1.405 \pm 0.0143^{\mathrm{a}}$ & $1.468 \pm 0.0109^{\mathrm{b}}$ & $1.445 \pm 0.0099^{\mathrm{ab}}$ & 0.002 \\
\hline
\end{tabular}

Values are mean \pm S.E.M. Significant $P$ values $(<0.05)$ are highlighted in bold.

*As embryo donor adiposity was without significant influence the biochemical data for recipients receiving embryos from control or obese donors was combined. Mean values within a row with unlike superscripts letters are significantly different, $P<0.05$. ${ }^{¥} \mathrm{Change}$ between pre-embryo transfer and late gestation concentration in same direction in all groups, $P<0.001$.

not change between embryo transfer and late gestation in the OTC group in keeping with the successful maintenance of adiposity score. In contrast, plasma leptin increased in overnourished dams with the greatest differential evident in recipients who were relatively thin at conception, again commensurate with their relatively higher increase in adiposity. At late gestation, plasma viscosity reflected initial recipient adiposity category and gestational intake and was lowest in the OTC group.

\section{Pregnancy outcome and supplementary feeding}

Pregnancy outcome data after spontaneous vaginal delivery at term are presented in Table 4. Relative to the OTC group, gestation length was shorter in the four overnourished groups but independent of both donor and recipient adiposity. Irrespective of treatment group, average live weight gain during the first two-thirds of gestation was negatively correlated with gestation length $(r=-0.636, P<0.001, n=74)$. Gestation length was positively associated with birth weight for the study population as a whole $(r=0.725, P<0.001)$ and within the overnourished $(r=0.621, P<0.001, n=55)$ and OTC groups separately $(r=0.548, P=0.015, n=19)$. Average lamb birth weight and height were independent of donor adiposity but reduced in initially thin vs fat recipients and lower than those in the OTC group. The differential in birth weight remained after adjusting individual birth weights to a theoretical standard 146 days of gestation. The proportion of lambs classified as IUGR was also independent of initial donor adiposity and was greater in recipients who were relatively thin vs fat at conception ( $70 \%$ and $36 \%$ respectively, compared with $5 \%$ in the OTC group). Similarly, the ratio of maternal weight change across gestation to birth weight was greater in thin than in fat recipients and both were higher than those in the OTC group. Total fetal cotyledon weights were also independent of donor adiposity but reduced in relatively thin vs fat recipient groups (77 vs $103 \mathrm{~g}$ ) and markedly lower than those in the OTC group (158g). The converse was true for placental efficiency as inferred from fetal:cotyledon weight, with thin $>$ fat $>$ OTC groups. The individual relationships between fetal cotyledon weight and lamb birth weight are shown in Fig. 3 with the strongest associations observed in the overnourished groups.

Nutrient partitioning to the mammary gland was also influenced by gestational intake. Colostrum yield at parturition was variable within all groups, but nevertheless positive relationships with fetal cotyledon weight and lamb birth weight were evident for the population as a whole $(r=0.523$ and 0.556 

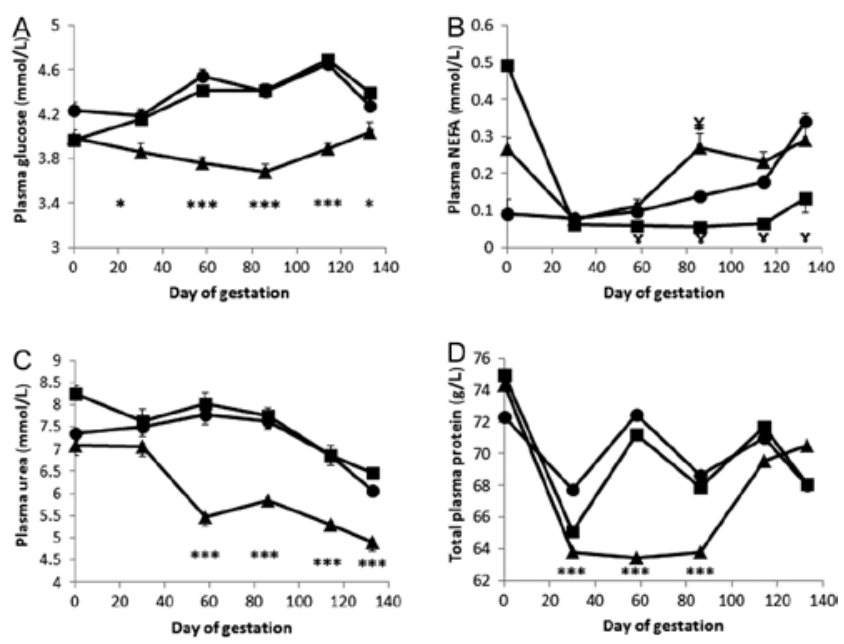

Figure 2 Peripheral plasma glucose (A), NEFA (B), urea (C) and protein (D) concentrations in samples collected at $\sim$ monthly intervals throughout pregnancy in adolescent ewes whose adiposity status varied at conception. All ewes received a single embryo and those classified as relatively fat (solid circle) or thin (solid square) at conception were overnourished throughout gestation to promote maternal growth/adiposity. Ewes with intermediate (control) adiposity at conception received a control ration to maintain initial adiposity and acted as optimally treated controls (solid triangle). Data comparison at each stage of gestation by one-way ANOVA followed post hoc by Tukey's method to differentiate between groups. Mean $( \pm$ S.E.M.) values are significantly different between control, and both fat and thin overnourished groups, $* P<0.05, * * * P<0.001$. Mean values are significantly different between control and fat overnourished group, ${ }^{¥} P<0.001$. Mean values are significantly different between thin and fat overnourished groups and between thin and control, ${ }^{r} P<0.001$.

respectively, $P<0.001)$. The OTC dams had a greater colostrum volume than overnourished dams and within the latter category yield was independent of donor and recipient adiposity (Table 4). IgG concentration was not influenced by donor or recipient adiposity or gestational intake but the greater yield in the OTC group meant that total IgG content was the highest in this group. Forty-five dams studied $(60 \%)$ were deemed to have insufficient colostrum to meet the initial minimum requirement of $50 \mathrm{~mL} / \mathrm{kg}$ body weight, and their offspring were all supplemented with frozen banked colostrum. Unsurprisingly, 29 lambs required further supplementation with colostrum/milk until an appropriate lactation and ewe-lamb bond were established. Both the number of lambs requiring supplementation and the frequency of supplementary feeds were independent of donor adiposity, recipient adiposity and gestational intake (Table 4).

\section{Neonatal viability and lamb growth rate}

Two IUGR male lambs (birth weights 2.15 and $1.92 \mathrm{~kg}$, born at 137 and 138 days gestation respectively) died in the early neonatal period. These individuals were both derived from different obese donors and were gestated by an initially thin and fat recipient respectively.

The absolute and current fractional growth rates of all viable lambs were documented until weaning at 11 weeks of age and were independent of both donor and recipient ewe adiposity. In contrast, prenatal growth status and to a much lesser extent, gender influenced growth (Fig. 4). Both absolute and current fractional growth rates (weight and height) of non-IUGR or normal birth weight lambs born to overnourished dams were equivalent to those of OTC offspring throughout the period of lactation. In contrast, prenatally growthrestricted (IUGR) lambs remained smaller at all time points $(P<0.001)$ in spite of exhibiting higher fractional growth between each week of measurement $(P<0.01)$. Irrespective of gestational intake and birth weight category, males were progressively heavier and taller than females from Day $42(P=0.044$ and $P=0.043$ respectively) until Day 77 (both $P=0.003$ ).

\section{Discussion}

Herein, we used assisted conception procedures to examine the impact of maternal obesity during oocyte development and its putative interaction with nutrient reserves at conception on pregnancy outcome in young adolescent sheep. Embryo recipient nutritional status at conception, but not pre-conception donor ewe obesity, modestly influenced the feto-placental growth trajectory while comparison with the optimally treated control group indicated that high gestational intakes to promote rapid maternal growth remain the dominant negative influence on pregnancy outcome in young adolescents.

\section{Donor ewe adiposity}

Notwithstanding achieving an $11 \%$ differential in adiposity and marked differences in circulating plasma leptin and lipid concentrations prior to embryo recovery, we found no evidence of a negative impact of relative maternal obesity ( $\sim 33 \%$ body fat) on ovulation, fertilisation or embryo recovery rates. This was somewhat unexpected as we have previously recorded a $48 \%$ reduction in ovulation rate after superovulation in long-term obese compared with control ewes of the same age and genotype (McConnell et al. 2004), whereas in beef and dairy cattle, there is an inverse relationship between adiposity and ovarian response (Velazquez 2015). Furthermore, exposure to ad libitum dietary intakes for 3 weeks prior to embryo recovery has been associated with a lower superovulation response both in terms of number of adult ewes ovulating and ovulation rate per ewe (Lozano et al. 2003), whereas obese women undergoing ART required a higher follicle-stimulating hormone ( $\mathrm{FSH}$ ) start dose to produce fewer oocytes (Zander-Fox et al. 2012). There is a large body of evidence connecting peri-conception diet 


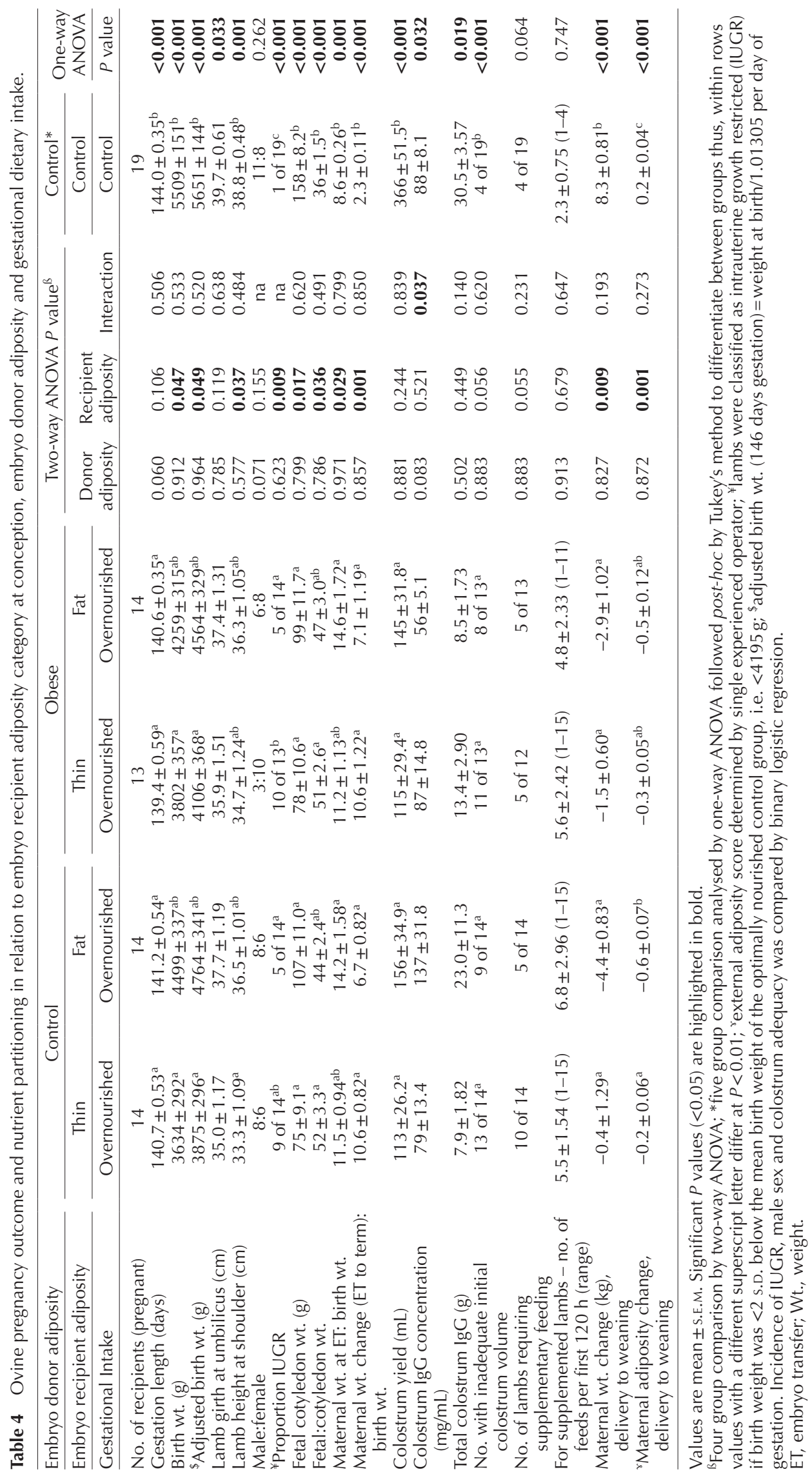




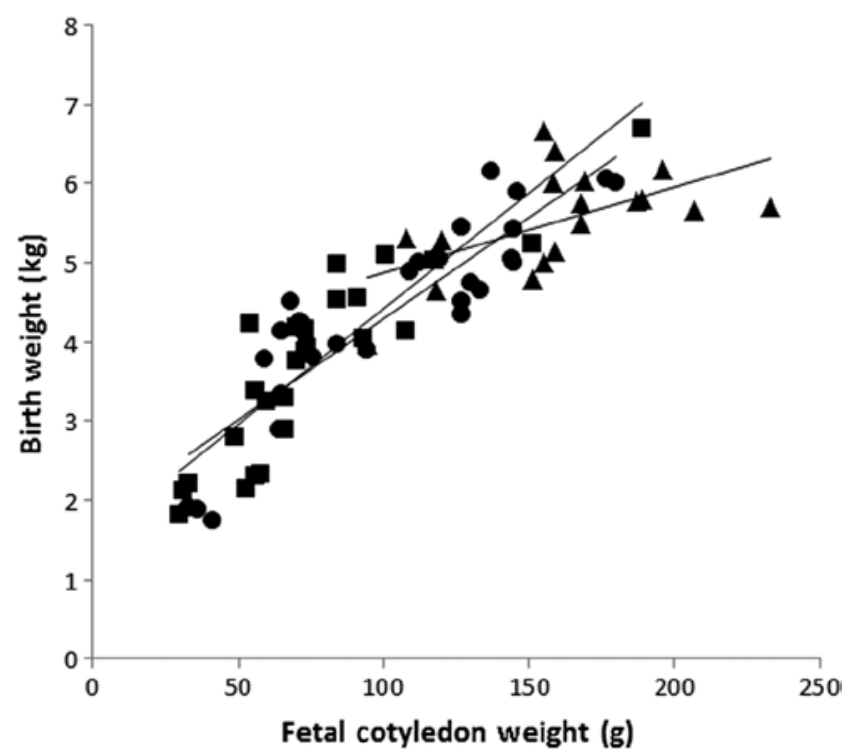

Figure 3 Association between total fetal cotyledon weight and lamb birthweight at term in relation to maternal adiposity status at conception and gestational intake thereafter. The adolescent dams were either relatively fat (solid circle; $r=0.878, P<0.001$ ) or thin (solid square; $r=0.888, P<0.001$ ) at conception and overnourished throughout gestation to promote maternal growth/adiposity or were of intermediate adiposity at conception, nourished to maintain initial adiposity and acted as optimally treated controls (solid triangle; $r=0.592, P=0.009)$.

and/or nutritional status with embryo quality. When the approach is similar to that used here (namely superovulation with $\mathrm{FSH}$, intrauterine insemination and embryo recovery at Day 4 or 6 of the cycle), there is little impact of either acute $(1.5 \times$ maintenance for 3 weeks $)$ or prolonged ( $1.8 \times$ maintenance for 4 months) elevations in adult donor ewe intake on the developmental stage or transferrable quality of the embryo (Kakar et al. 2005,
Rattanatray et al. 2010). In contrast, there is evidence that when oocytes are either fertilised and matured in vitro, or fertilised in vivo and cultured in vitro, overfeeding and/or obesity in the donors has a negative effect on fertilisation rate and on the rate of morula/blastocyst development (adult sheep, Grazul-Bilska et al. 2012: late adolescent mouse, Finger et al. 2015, Wu et al. 2015: young cattle, Adamiak et al. 2005). In the present study, any similar delay in embryo development in vivo would have resulted in lower embryo recovery rates and/ or morulae with a low cell count for stage (and hence deemed non-transferrable), but we found no evidence that this was the case. Thus, either the nutritional microenvironment surrounding the oocyte in the follicle and the early embryo in the oviduct is largely independent of the donor's nutritional and hormonal status or the oocyte/embryo is relatively insensitive to local changes in nutrients at this early stage.

In the present study, only grade- 1 morulae, correct for stage, were transferred in singleton to the embryo recipients. This is the only viable approach when recovering embryos at a defined time point for immediate transfer into synchronous recipients because delayed development cannot be accurately differentiated from poor quality. Here, we evaluated the putative interaction between donor and recipient adiposity for the first time. Contrary to our hypothesis, we found that the nutritional status of the embryo donor did not influence pregnancy rate or conceptus growth in adolescents subsequently overnourished to promote rapid gestational weight gains and continued maternal body growth. Few of the aforementioned ruminant studies have documented the impact of relative maternal obesity beyond the maternal recognition of pregnancy stage. Exceptionally in the study by Rattanatray and coworkers (Rattanatray et al. 2010), embryos from obese

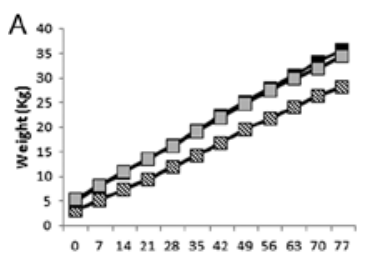

Age (days)
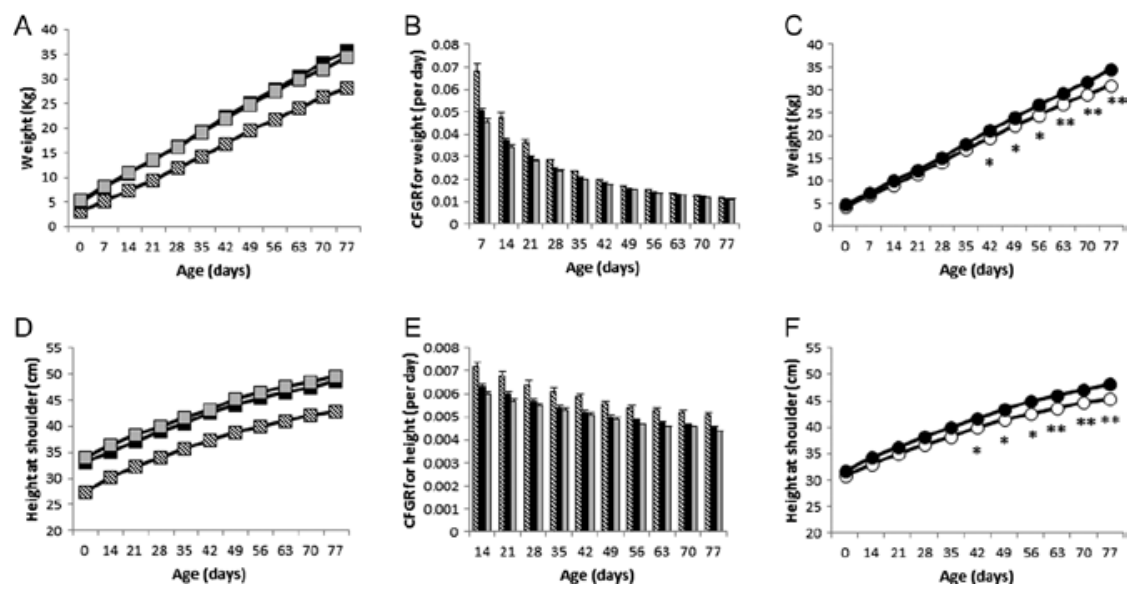

Figure 4 Absolute changes in postnatal weight and height determined weekly (A, D), and current fractional growth rate (CFGR) during weekly periods from birth until weaning $(B, E)$ in intrauterine growth-restricted (IUGR: striped grey bar/square; $n=27$ ) and non-IUGR (solid black bar/square; $n=26$ ) lambs from overnourished adolescent dams and in normal birth weight lambs from optimally treated controls (solid grey bar/square; $n=18$ ), with males and females combined. Data comparison at each age by one-way ANOVA followed post hoc by Tukey's method to differentiate between groups. Mean values are significantly different between IUGR compared with non-IUGR and normal birth weight lambs at all ages. For $\mathrm{A}$ and $\mathrm{D}, P<0.001$ and for $\mathrm{B}$ and $\mathrm{E}, P<0.01$. Changes in weight and height $(\mathrm{C}, \mathrm{F})$ in males (solid black circle; $n=34$ ) and females (closed white circle; $n=38$ ), irrespective of birth weight classification and gestational intake, $* P<0.05, * * P<0.01$. 
or control ewes were transferred singly into non-obese adult recipients. Although recipient conception rate and gestational weight gain were not expressly reported, the authors indicate that peri-conception obesity did not influence birth weight. Studies in mice are somewhat contradictory: when oocytes harvested from the Blobby mouse strain were in vitro fertilised and blastocysts were transferred into normal-weight recipients, the resulting fetuses were heavier than controls at E14.5 (Wu et al. 2015). In contrast, when the contribution of diet-induced obesity in both parents was assessed after natural mating or embryo transfer into normal weight recipients, conception rate was unaffected, but fetal and placental weights were reduced at E19, independent of in utero diet exposure (McPherson et al. 2015). However, these mouse studies (conducted in late adolescence) require groups of embryos ( $n=5$ or 6 ) to be transferred together to ensure conception in this litter-bearing species, and this somewhat confounds the assessment of feto-placental growth, arguably not accurately replicating the human condition. Women undergoing ART may help inform the debate but, even although obese adult women undergoing IVF with autologous oocytes are variously linked with reduced fertilisation rates, lower embryo quality, increased miscarriage rates, fewer clinical intrauterine pregnancies and live births (Luke et al. 2011, Rittenberg et al. 2011, Shah et al. 2011, Provost et al. 2016), there is a relative lack of information on other key aspects of pregnancy outcome. A single study involving 739 embryo transfers has reported a 70-200g increase in singleton term fetal weight in obese compared with normal BMI women (Zander-Fox et al. 2012) and, in a larger population assessment of singleton pregnancies, obese women who used ART to conceive $(n=338)$ had a two-fold higher risk of early preterm birth $(<34$ weeks gestation) than those who conceived naturally ( $n=105,650$, Sauber-Schatz et al. 2012). In both of these studies, however, it is not possible to separate effects of pre-pregnancy BMI from gestational intake thereafter.

\section{Recipient ewe adiposity}

Independent of donor ewe adiposity, adolescent recipients who were relatively thin at conception and who were subsequently overnourished to promote continued maternal growth throughout pregnancy delivered lambs that were on average $665 \mathrm{~g}$ lighter than recipients who were fat at conception. This is strikingly similar to the differential in birth weight attributed to recipient adiposity previously (555g) when donor ewe nutrition was not varied and equated to the control donor group used here (Wallace et al. 2010). Together, our present and previous studies suggest that adiposity at conception is an important consideration in predicting pregnancy outcome in still-growing adolescents (see below). The difference in estimated body fat between recipient groups was quite small $(8.8 \%)$, but nevertheless at the point of embryo transfer, those classified as relatively thin had lower peripheral nutrient and metabolic hormone concentrations (glucose, iron and leptin), whereas their high lipid levels were indicative of active catabolism. Nonetheless, these small but significant differences in maternal nutrient status at conception were sufficient to differentially impact placental growth and hence fetal nutrient supply, leading to a higher incidence of IUGR in the initially thin vs fat groups. This occurred in spite of presumed placental adaptation and greater transplacental nutrient transport efficiency, as inferred from a higher fetal: placental weight ratio in the thin group. A similar relationship between nutrient status and placental growth is inferred in humans, irrespective of age, because placental weight rises with increasing maternal BMI at conception from underweight through to morbidly obese categories (Wallace et al. 2012). In infertile women the use of donor oocytes is now common and while the impact of donor vs recipient BMI on pregnancy, miscarriage and live-births has been related (Jungheim et al. 2013, Rubio et al. 2015), potential effects on gestation length, placental size and birth weight have not been reported.

\section{Gestational intake}

In the present study, the slow-growing age-matched contemporaneous control group was included as a reference point for normal fetal growth. The nutritional management of this group, in terms of donor and recipient adiposity and gestational intake, replicated our standard approach and comparison with the overnourished groups, irrespective of initial recipient adiposity, serves to emphasise that high gestational intakes to promote rapid maternal growth remain the most dominant negative influence on pregnancy outcome in young adolescent sheep. This was true with respect to premature delivery, feto-placental growth and nutrient partitioning to the mammary gland, all of which confirmed prior studies with respect to the magnitude of effects (Wallace 2011) and was also evident in the differences in maternal biochemical/metabolic status during gestation and at the late gestation time point. High circulating glucose and urea (and low NEFA) concentrations are commensurate with the oversupply of nutrients facilitating a highly anabolic state, rapid growth and increased adiposity in overnourished dams. This rapid maternal growth has previously been linked to depletion of liver iron stores during the first two thirds of gestation, and with a failure of the normal blood volume expansion of pregnancy between mid and late gestation (Luther et al. 2010). Here, compared with the OTC group, the relative preservation of haematocrit, haemoglobin and plasma protein concentrations between the point of embryo transfer and late gestation in overnourished dams implies a similar scenario. In support, blood viscosity was highest in the overnourished dams that were relatively thin at conception, and this is likely to play a role in 
the attenuation of uteroplacental blood flows and fetal nutrient supply characteristic of this animal model.

\section{Postnatal growth}

Although fetal growth was constrained by both recipient adiposity at conception and gestational intake in the current study, the degree of compromise at birth was variable. Accordingly, it was prenatal growth category and to a lesser extent gender which had the most marked influence on early postnatal growth. Fractional growth rates were high in IUGR lambs, and they remained smaller at weaning, but the long-term implications beyond this life-stage were not determined. Others have reported programmed changes in later adiposity and metabolism in prepubertal and adult ovine offspring after peri-conception obesity in adult ewes, but these effects were independent of changes in birth weight (Long et al. 2010, Rattanatray et al. 2010).

\section{Implications for human adolescents}

No animal model completely replicates human pregnancy, but nevertheless, the outcome of the current ovine study has implications for public health. For young adolescent girls, it seems that both nutrient reserves at conception and dietary intake thereafter are likely to be potent determinants of fetal growth particularly if maternal growth per se is ongoing or incomplete. Where early marriage soon after menarche and pregnancy during young adolescent life is the cultural norm, girls with a low $\mathrm{BMI}$ should be encouraged to gain weight and achieve a normal $\mathrm{BMI}$ and hence adequate nutrient status before pregnancy. Thereafter, dietary intakes should be sufficient to maintain maternal adiposity throughout gestation and thereby meet fetal nutrient requirements particularly during the final rapid growth phase. Gauging changes in skinfold thickness in addition to monitoring weight gain may be a simple and effective tool enabling health professionals to achieve this. Where adolescent pregnancies are unplanned and calorie intakes are predicted to be high, the mother should be advised of the dangers of excessive weight gain during pregnancy, particularly during the period spanning placental proliferation. Further, as the placenta is pivotal to mediating adverse pregnancy outcome in the young still-growing adolescent, early diagnosis of deficiencies in uteroplacental growth and/or blood flow by ultrasound are likely to be beneficial for identifying those at risk of fetal compromise and IUGR.

Using ART in the present study, we were able to largely uncouple pre-, peri- and post-conception nutritional exposures to judge their separate or interdependent influences. The clear conclusion from our novel design is that nutritional status at conception and nutritional intake thereafter influenced the placental growth trajectory, birth weight and the incidence of marked prenatal growth restriction, with nutritional intake after conception having the most pronounced effect in sheep. Somewhat contrary to expectation, there was no evidence that pre-conception obesity (equivalent to $\sim 33 \%$ body fat) negatively influenced embryo quality, conception rate or conceptus growth after embryo transfer into adolescent recipients. The public health implications specific to human adolescents of varying body fatness and growth status have been outlined previously. In addition, the data suggest that the focus for optimising the nutritional management of animals undergoing commercial ART for genetic improvement purposes should be the adiposity and gestational weight gain of the recipient rather than the adiposity status of the donor animal. Similarly those breeding ewes naturally in the first year of life (adolescents) need to appreciate that nutritional status at conception and dietary intake thereafter play an important and potentially modifiable role in maximising offspring birth weight and subsequent growth rate.

\section{Declaration of interest}

The authors declare that there is no conflict of interest that could be perceived as prejudicing the impartiality of the research reported.

\section{Funding}

Funded by the Scottish Government's Rural and Environment Science and Analytical Services Division (RESAS), including the Strategic Partnership for Animal Science Excellence (SPASE).

\section{Acknowledgement}

Graham Horgan (BioSS, Aberdeen, UK) provided statistical advice.

\section{References}

Adamiak SJ, Mackie K, Watt RG, Webb R \& Sinclair KD 2005 Impact of nutrition on oocyte quality: cumulative effects of body composition and diet leading to hyperinsulinemia in cattle. Biology of Reproduction 73 918-926. (doi:10.1095/biolreprod.105.041483)

AFRC Energy and Protein Requirements of Ruminants 1993 An Advisory Manual Prepared by the AFRC Technical Committee on Responses to Nutrients. Wallingford, UK: CAB International.

Anderson NH, Sadler LC, Stewart AW, Fyfe EM \& McCowan LME 2013 Independent risk factors for infants who are small for gestational age by customised birthweight centiles in a multi-ethnic New Zealand population. Australian and New Zealand Journal of Obstetrics and Gynaecology 53 136-142. (doi:10.1111/ajo.12016)

Aune D, Saugstad OD, Henriksen T \& Tonstad S 2014 Maternal body mass index and the risk of fetal death, stillbirth, and infant death: a systematic review and meta-analysis. Journal of the American Medical Association 311 1536-1546. (doi:10.1001/jama.2014.2269)

Carr DJ, Aitken RP, Milne JS, David AL \& Wallace JM 2012 Fetoplacental biometry and umbilical artery Doppler velocimetry in the overnourished adolescent model of fetal growth restriction. American Journal of Obstetrics and Gynecology 207 e6-e15. (doi:10.1016/j. ajog.2012.05.008) 
Cooke BM \& Stuart J 1988 Automated measurement of plasma viscosity by capillary viscometer. Journal of Clinical Pathology 41 1213-1216. (doi:10.1136/jcp.41.11.1213)

Finger BJ, Harvey AJ, Green MP \& Gardner DK 2015 Combined parental obesity negatively impacts preimplantation mouse embryo development, kinetics, morphology and metabolism. Human Reproduction 30 2084-2096. (doi:10.1093/humrep/dev142)

Frisancho AR 1997 Reduction of birth weight among infants born to adolescents: maternal-fetal growth competition. Annals of the New York Academy of Sciences $\mathbf{8 1 7}$ 272-280. (doi:10.1111/j.1749-6632.1997. tb48213.x)

Frisancho AR, Matos J, Leonard WR \& Yaroch L 1985 Developmental and nutritional determinants of pregnancy outcome among teenagers. American Journal of Physical Anthropology 66 247-261. (doi:10.1002/ ajpa.1330660302)

Ganchimeg T, Mori R, Ota E, Koyanagi A, Gilmour S, Shibuya K, Torloni MR, Betran AP, Seuc A, Vogel J et al. 2013 Maternal and perinatal outcomes among nulliparous adolescents in low-and middle-income countries: a multi-country study. British Journal of Obstetrics and Gynaecology 120 1622-1630. (doi:10.1111/1471-0528.12391)

Gonzalez-Aňover P, Encinas T, Tores-Rovira L, Pallares P, MuňozFrutos J, Gomez-Izquiredo E, Sanchez-Sanchez R \& Gonzalez-Bulnes A 2011 Ovulation rate, embryo mortality and intrauterine growth retardation in obese swine with gene polymorphisms for leptin and melanocortin receptors. Theriogenology 75 34-41. (doi:10.1016/j. theriogenology.2010.07.009)

Grazul-Bilska AT, Borowczyk E, Bilski JJ, Reynolds LP, Redmer DA, Caton JS \& Vonnahme KA 2012 Overfeeding and underfeeding have detrimental effects on oocyte quality measured by in vitro fertilization and early embryonic development in sheep. Domestic Animal Endocrinology 43 289-298. (doi:10.1016/j.domaniend.2012.05.001)

Hanson MA \& Gluckman PD 2015 Developmental origins of health and disease - global health implications. Best Practice and Research Clinical Obstetrics and Gynaecology 29 24-31. (doi:10.1016/j. bpobgyn.2014.06.007)

Jungheim ES, Schon SB, Schulte MB, DeUgarte DA, Fowler SA \& Tuuli MG 2013 IVF outcome in obese donor oocyte recipients: a systematic review and meta-analysis. Human Reproduction 28 2720-2727. (doi:10.1093/ humrep/det292)

Kakar MA, Maddocks S, Lorimer MF, Kleeman DO, Rudiger SR, Hartwich KM \& Walker SK 2005 The effect of peri-conception nutrition on embryo quality in the superovulated ewe. Theriogenology 64 1090-1103. (doi:10.1016/j.theriogenology.2004.12.017)

Kozuki N, Lee AC, Silveira MF, Sania A, Vogel JP, Adair L, Barros F, Caulfield LE, Christian P, Fawzi W et al. 2013 The associations of parity and maternal age with small-for-gestational-age, preterm, and neonatal and infant mortality: a meta-analysis. BMC Public Health 13 (Supplement 3) S2. (doi:10.1186/1471-2458-13-S3-S2)

Kumbak B, Oral E \& Bukulmez O 2012 Female obesity and assisted reproductive technologies. Seminars in Reproductive Medicine 30 507-516. (doi:10.1055/s-0032-1328879)

Long NM, George LA, Uthlaut AB, Smith DT, Nijland MJ, Nathanielsz PW \& Ford SP 2010 Maternal obesity and increased nutrient intake before and during gestation in the ewe results in altered growth, adiposity, and glucose tolerance in adult offspring. Journal of Animal Science $\mathbf{8 8}$ 3546-3553. (doi:10.2527/jas.2010-3083)

Lozano JM, Lonergan P, Boland MP \& O'Callaghan S 2003 Influence of nutrition on the effectiveness of superovulation programmes in ewes: effect on oocyte quality and post-fertilization development. Reproduction 125 543-553. (doi:10.1530/rep.0.1250543)

Luke B, Brown MB, Missmer SA, Bukulmez O, Leach R \& Stern JE 2011 The effect of increasing obesity on the response to and outcome of assisted reproductive technology: a national study. Fertility and Sterility 96 820-825. (doi:10.1016/j.fertnstert.2011.07.1100)

Luther JS, Aitken RP, Milne JS, McArdle HJ, Gambling L, Reynolds LP, Redmer DA \& Wallace JM 2010 Liver iron status and associated haematological parameters in relation to fetal growth and pregnancy outcome in rapidly growing adolescent sheep carrying a singleton lamb derived by embryo transfer. Reproduction Fertility Development 22 1230-1236. (doi:10.1071/RD10030)

Lutsiv O, Mah J, Beyene J \& McDonald SD 2015 The effects of morbid obesity on maternal and neonatal health outcomes: a systematic review and meta-analyses. Obesity Reviews 16 531-546. (doi:10.1111/ obr.12283)

Malabarey OT, Balayla J, Klam SL, Shrim A \& Abenhaim HA 2012 Pregnancies in young adolescent mothers: a population-based study on 37 million births. Journal of Pediatric and Adolescent Gynecology 25 98-102. (doi:10.1016/j.jpag.2011.09.004)

Marie M, Findlay PA, Thomas L \& Adam CL 2001 Daily patterns of plasma leptin in sheep: effects of photoperiod and food intake. Journal of Endocrinology 170 277-286. (doi:10.1677/joe.0.1700277)

Marchi J, Berg M, Dencker A, Olander EK \& Begley C 2015 Risks associated with obesity in pregnancy, for the mother and baby: a systematic review of reviews. Obesity Reviews 16 621-638. (doi:10.1111/obr.12288)

McConnell JM, Aitken RP, Petrie L \& Wallace JM 2004 Maternal fatness alters mitochondrial activity and the mitochondrial genome during oocyte maturation. Journal of the Society of Gynecologic Investigation 11 (Supplement 2) 294A-295A. (doi:10.1016/j.jsgi.2004.02.003)

McDonald SD, Han Z, Mulla S \& Beyene J 2010 Overweight and obesity in mothers and risk of preterm birth and low birth weight infants: systematic review and meta-analyses. BMJ Clinical Research Education 341 c3428. (doi:10.1136/bmj.c3428)

McMillan WH \& McDonald MF 1985 Survival of fertilised ova from ewe lambs and adult ewes in the uteri of ewe lambs. Animal Reproduction Science 8 235-240. (doi:10.1016/0378-4320(85)90028-4)

McPherson NO, Bell VG, Zander-Fox DL, Fullston T, Wu LL, Robker RL \& Lane M 2015 When two obese parents are worse than one! Impacts on embryo and fetal development. American Journal of Physiology, Endocrinology and Metabolism 309 E568-E581. (doi:10.1152/ ajpendo.00230.2015)

Provost MP, Acharya KS, Acharya CR, Yeh JS, Steward RG, Eaton JL, Goldfarb JM \& Muasher SJ 2016 Pregnancy outcomes decline with increasing recipient body mass index: an analysis of 22,317 fresh donor/ recipient cycles from the 2008-2010 Society for Assisted Reproduction Technology Clinic outcome reporting system registry. Fertility and Sterility 105 364-368. (doi:10.1016/j.fertnstert.2015.10.015)

Purcell SH \& Moley KH 2011 The impact of obesity on egg quality. Journal of Assisted Reproduction and Genetics 28 517-524. (doi:10.1007/ s10815-011-9592-y)

Quirke JF \& Hanrahan JP 1977 Comparison of the survival in the uteri of adult ewes of cleaved ova from adult ewes and ewe lambs. Journal of Reproduction and Fertility 51 487-489. (doi:10.1530/jrf.0.0510487)

Rattanatray L, MacLaughlin SM, Kleeman DO, Walker SK, Muhlhausler BS \& McMillen IC 2010 Impact of maternal periconceptional overnutrition on fat mass and expression of adipogenic and lipogenic genes in visceral and subcutaneous fat depots in the postnatal lamb. Endocrinology 151 5195-5205. (doi:10.1210/en.2010-0501)

Rittenberg V, Seshadri S, Sunkara SK, Sobaleva S, Oteng-Ntim E \& El-Toukhy T 2011 Effect of body mass index on IVF treatment outcome: an updated systematic review and meta-analysis. Reproductive BioMedicine Online 23 421-439. (doi:10.1016/j.rbmo.2011.06.018)

Rubio C, Vassena R, Garcia D, Vernaeve V \& Madero JI 2015 Influence of donor, recipient, and male partner body mass index on pregnancy rates in oocyte donation cycles. JBRA Assisted Reproduction 19 53-58. (doi:10.5935/1518-0557.20150013)

Russel AJF, Doney JM \& Gunn RG 1969 Subjective assessment of body fat in live sheep. Journal of Agricultural Science 72 451-454. (doi:10.1017/ S0021859600024874)

Sauber-Schatz EK, Sappenfield W, Grigorescu V, Kulkarni A, Zhang Y, Salihu HM, Rubin LP, Kirby RS, Jamieson DJ \& Macaluso M 2012 Obesity, assisted reproductive technology, and early preterm birth Florida, 2004-2006. American Journal of Epidemiology 176 886-896. (doi:10.1093/aje/kws155)

Shah DK, Missmer SA, Berry KF, Racowsky C \& Ginsburg ES 2011 Effect of obesity on oocyte and embryo quality in women undergoing in vitro fertilization. Obstetrics and Gynecology 118 63-70. (doi:10.1097/ AOG.0b013e31821fd360)

Scholl TO, Hediger ML, Schall JI, Khoo CS \& Fischer RL 1994 Maternal growth during pregnancy and the competition for nutrients. American Journal of Clinical Nutrition 60 183-201.

Scholl TO, Hediger ML \& Schall JI 1997 Maternal growth and fetal growth: pregnancy course and outcome in the Camden study. Annals of the New York Academy of Science 81 292-301. (doi:10.1111/j.1749-6632.1997. tb48215.x) 
Sharma D, Shastri S \& Sharma P 2016 Intrauterine growth restriction: antenatal and postnatal aspects. Clinical Medicine Insights: Pediatrics $\mathbf{1 0}$ 67-83. (doi:10.4137/CMPed.S40070)

Shrim A, Ates S, Mallozzi A, Brown R, Ponette V, Levin I, Shehata F \& Almog B 2011 Is young maternal age really a risk factor for adverse pregnancy outcome in a Canadian tertiary referral hospital? Journal of Pediatric Adolescent Gynecology 118 741-747. (doi:10.1016/j.jpag.2011.02.008)

Sinclair K \& Watkins AJ 2014 Parental diet, pregnancy outcomes and offspring health: metabolic determinants in developing oocytes and embryos. Reproduction, Fertility and Development 26 99-114. (doi:10.1071/RD13290)

Torvie AJ, Callegari LS, Schiff MA \& Debiec KE 2015 Labour and delivery outcomes among young adolescents. American Journal of Obstetrics and Gynecology 213 95.e1-8. (doi:10.1016/j.ajog.2015.04.024)

Velazquez MA 2015 Impact of maternal malnutrition during the periconception period on mammalian preimplantation embryo development. Domestic Animal Endocrinology 51 27-45. (doi:10.1016/j. domaniend.2014.10.003)

Wallace JM 2011 Adaptive maternal, placental and fetal responses to nutritional extremes in the pregnant adolescent: lessons from sheep. In Reproduction and Adaptation, pp 112-127. Eds CGN Mascie-Taylor \& L Rosetta. Cambridge: Cambridge University Press.

Wallace JM, Aitken RP \& Cheyne MA 1996 Nutrient partitioning and fetal growth in rapidly growing adolescent ewes. Journal of Reproduction and Fertility 107 183-190. (doi:10.1530/jrf.0.1070183)

Wallace JM, DaSilva P, Aitken RP \& Cruickshank MA 1997 Maternal endocrine status in relation to pregnancy outcome in rapidly growing adolescent sheep. Journal of Endocrinology 155 359-368. (doi:10.1677) joe.0.1550359)

Wallace JM, Bourke DA, Aitken RP \& Cruickshank MA 1999 Switching maternal dietary intake at the end of the first trimester has profound effects on placental development and fetal growth in adolescent ewes carrying singleton fetuses. Biology of Reproduction 61 101-110. (doi:10.1095/biolreprod61.1.101)

Wallace JM, Aitken RP, Milne JS \& Hay WW Jr 2004 Nutritionally mediated placental growth restriction in the growing adolescent: consequences for the fetus. Biology of Reproduction 71 1055-1062. (doi:10.1095/ biolreprod.104.030965)

Wallace JM, Luther JS, Milne JS, Aitken RP, Redmer DA, Reynolds LP \& Hay WW Jr2006a Nutritional modulation of adolescent pregnancy outcome - a review. Placenta 27 S61-S68. (doi:10.1016/j.placenta.2005.12.002)
Wallace JM, Milne JS, Redmer DA \& Aitken RP $2006 b$ Effect of diet composition on pregnancy outcome in overnourished rapidly growing adolescent sheep. British Journal of Nutrition 96 1060-1068. (doi:10.1017/BJN20061979)

Wallace JM, Milne JS \& Aitken RP 2010 Effect of weight and adiposity at conception and wide variations in gestational dietary intake on pregnancy outcome and early postnatal performance in young adolescent sheep. Biology of Reproduction 82 320-330. (doi:10.1095/ biolreprod.109.080069)

Wallace JM, Horgan GW \& Bhattacharya S 2012 Placental weight and efficiency in relation to maternal body mass index and the risk of pregnancy complications in women delivering singleton babies. Placenta 33 611-618. (doi:10.1016/j.placenta.2012.05.006)

Weng YH, Yang CY \& Chiu YW 2014 Risk assessment of adverse birth outcomes in relation to maternal age. PLOS ONE 9 e114843. (doi:10.1371/journal.pone.0114843)

World Health Organization (WHO) 2012 Born too soon: the global action report on preterm birth. (Available at: http://www.who.int/pmnch/media/ news/2012/201204_borntoosoon-report.pdf). Accessed on 18 October 2016.

Wu LL, Russell DL, Wong SL, Chen M, Tsai T, St John JC, Norman RJ, Febbraio MA, Carroll J \& Robker RL 2015 Mitochondrial dysfunction in oocytes of obese mothers: transmission to offspring and reversal by pharmacological endoplasmic reticulum stress inhibitors. Development 142 681-691. (doi:10.1242/dev.114850)

Zander-Fox DL, Henshaw R, Hamilton H \& Lane M 2012 Does obesity really matter? The impact of BMI on embryo quality and pregnancy outcomes after IVF in women aged $\leq 38$ years. Australian and New Zealand Journal of Obstetrics and Gynaecology 52 270-276. (doi:10.1111/j.1479828X.2012.01453.x)

Received 2 November 2016

First decision 30 November 2016

Revised manuscript received 9 December 2016

Accepted 9 January 2017 